\title{
Prevalence and Control of Hypertension in Iraqi Diabetic Patients: A Prospective Cohort Study
}

\author{
Abbas Ali Mansour* \\ Department of Medicine, Basrah College of Medicine, Basrah, Iraq
}

\begin{abstract}
Objectives: Diabetes and hypertension are major risk factors for cardiovascular disease, a leading cause of death in humans. The aim of our study was to determine the prevalence of hypertension, and hypertension control among adults with diabetes in Basrah (Southern Iraq).

Methods: A prospective cohort study was conducted at Al-Faiha Diabetes and Endocrine Center in Basrah. It was started in August 2008 to April 2011. The total number of recruited patients with diabetes was 5578.

Results: Hypertensive diabetic patients constituted $89.6 \%$ of this study cohort, with $45.3 \%$ of them newly discovered in the center. From hypertensive patients, $48.2 \%$ achieved the target blood pressure of less than 130/80 mmHg. The results of the multivariate analyses showed that the factors independently associated with the hypertension were aged $>50$ years (odds ratio, $0.4 ; 95 \%$ CI, 0.3 to $0.5 ; \mathrm{p}<0.001$ ), body mass index equal or more than 25 (odds ratio, $0.5 ; 95 \%$ CI, 0.4 to $0.6 ; \mathrm{p}<0.001$ ), insulin use (odds ratio, $0.6 ; 95 \% \mathrm{CI}, 0.5$ to $0.8 ; \mathrm{p}<0.001$ ) and duration of diabetes $>5$ years (odds ratio, $0.6 ; 95 \% \mathrm{CI}, 0.5$ to $0.7 ; \mathrm{p}<0.001)$.

Conclusion: This study confirmed that hypertension was seen in $\sim 90 \%$ of diabetic patients in Iraq, and approximately half of them were achieving target blood pressure level.
\end{abstract}

Keywords: Diabetes mellitus, hypertension, control, prevalence, Iraq.

\section{INTRODUCTION}

Diabetes and hypertension are major risk factors for cardiovascular disease, a leading cause of death in humans [1]. Insulin resistance and hyperglycemia combine to make hypertension more prevalent in the type 2 diabetic patient [2]. Approximately $15 \%$ of hypertensive patients are diabetic and approximately $75 \%$ of Type 2 diabetic patients are hypertensive [3].

The American Diabetes Association (ADA) in 2002, defined hypertension in diabetic patients as blood pressure (BP) $\geq 140 / 90 \mathrm{mmHg}$ and a target $\mathrm{BP}$ goal of $<130 / 80$ $\mathrm{mmHg}$ is reasonable [4]. For the first time the ADA and the Canadian Diabetes Association in 2008 stated that repeat systolic BP $\geq 130 \mathrm{mmHg}$ or diastolic $\mathrm{BP} \geq 80 \mathrm{mmHg}$ confirms a diagnosis of hypertension in patients with diabetes mellitus $[5,6]$.

The goal for BP in the type 2 diabetic patients is < $130 / 80 \mathrm{mmHg}$, and when significant proteinuria is present at $120 / 75 \mathrm{mmHg}$ or below [7-9]. Control of hypertension in the diabetic patient to the recommended level of below 130/80 $\mathrm{mmHg}$ has been shown to decrease both the microvascular and macrovascular complications of diabetes [2].

*Address correspondence to this author at the Department of MedicineBasrah College of Medicine. Consultant Physician -Al-Faiha Diabetes and Endocrine Center, Hattin post office P.O. Box: 142 Basrah - 42002- Iraq; Tel: +964 7801403706; E-mail: aambaam@yahoo.com
The aim of the study was to determine prevalence of hypertension, and hypertension control among adults (18 years of age and above) with diabetes in Basrah (Southern Iraq).

\section{METHODS}

\section{Setting}

A prospective cohort study was conducted at Al-Faiha Diabetes and Endocrine Center in Basrah. This center is the only center for this specialty in Southern Iraq. Its tertiary referral center received diabetic patients with failure of oral antihyperglycemic drugs from primary health care centers and hospitals in Basrah. This center started in August 2008 to concentrate on hypertension control besides glycemic and lipid control in patients with diabetes mellitus. Patients age $<$ 18 years, those with less than 6 months of follow-up, defaulters for more than 6 months or pregnant women, were excluded. The total recruited patients with diabetes were 5578, until end of April 2011. The patients were visiting the center every 2 months, and during each visit anthropometric studies were done with measurement of $\mathrm{BP}$ and blood glucose and $\mathrm{HbAlc}$ according to the indication.

\section{Definitions of the Variables}

Duration of diabetes was calculated as the patient's age at the time of the registration in the center minus age at onset of diabetes. Body Mass Index (BMI) was calculated as weight in $\mathrm{kg}$ divided by the square of height in $\mathrm{m}$. 
Current smokers were defined as those who reported smoking $>100$ cigarettes during their lifetime and were currently smoking every day or some days. Ex-smokers were defined as ever smokers who no longer smoked.

BP was measured by a nurse trained in the method using a mercury sphygmomanometer and appropriately sized arm cuffs after patients rested for 5 min seated.

Hypertension in diabetic patients was confirmed if systolic BP was equal or more than $130 \mathrm{mmHg}$ and or diastolic BP equal or more than $80 \mathrm{mmHg}$ on 2 occasions separated by at least 1 day or more, or on medications for hypertension [10].

For new hypertensive patients with a systolic BP of 130 $139 \mathrm{mmHg}$ or a diastolic BP of $80-89 \mathrm{mmHg}$, treatment was given as lifestyle/behavioral therapy alone for a maximum of 3 months and then, if targets are not achieved, they were treated pharmacologically with agents that block the renin-angiotensin system. Patients with hypertension (systolic $\mathrm{BP} \geq 140 \mathrm{mmHg}$ or diastolic $\mathrm{BP} \geq 90 \mathrm{mmHg}$ ) were given drug therapy in addition to lifestyle/behavioral therapy [10]. Drug therapy was titrated according to algorithms used by most centers [2]. In brief patients started candesartan 8 $\mathrm{mg}$ once daily gradually increased dose until $16 \mathrm{mg}$ once daily or enalapril $10 \mathrm{mg}$ twice daily, gradually increased dose to $20 \mathrm{mg}$ twice daily over 2-6 months. If this failed to achieve the target, hydrochlorothiazide $12.5 \mathrm{mg}$ once daily was added, gradually increasing the dose to $25 \mathrm{mg}$ daily. Patients still having a BP control out of target were given amlodipine $5 \mathrm{mg}$ daily as third drug. Patients on beta-blockers for associated ischemic heart disease or furosemide for heart failure were continued. Patients already hypertensive and on medication other than above therapies were changed to the above drugs gradually. Single agents were enough to control BP in $15 \%$ of patients, 2 drugs needed in $55 \%$ and 3 drugs ultimately needed in $30 \%$. Drugs were supplied free of charge.

Data analysis was done after April 2011. Any patients with systolic BP $<130 \mathrm{mmHg}$ and or diastolic $\mathrm{BP}<80$ $\mathrm{mmHg}$ at the last visit were considered to have controlled BP.

\section{STATISTICAL ANALYSES}

Statistical Package SPSS for Windows, version 18.0 (SPSS Inc), was used for statistical analysis. The mean \pm SD was determined for qualitative data, and frequency for categorical variables. The Chi-square test was used to analyze group differences for categorical variables, $t$-test for continuous variables and a $p$ value of $<0.05$ was considered significant. Multivariate analyses using logistic regression was used to study factors independently associated with hypertension.

\section{RESULTS}

More women (Table 1) were included in this study (55.6 vs $44.4 \%$ ). The mean age was $51.4 \pm 13.7$ years, with $56.3 \%$ of them aged more than 50 years. About $70.6 \%$ of our patients were either overweight or obese. Current smokers constituted $12.8 \%$. Most of the patients were on insulin (71.8\%), because of the duty of the center that is explained
Table 1. Baseline Characteristics

\begin{tabular}{|c|c|c|}
\hline Variables & & $\mathrm{n}(\%)$ \\
\hline \multirow[t]{2}{*}{ Gender } & Men & $2477(44.4)$ \\
\hline & Women & $3101(55.6)$ \\
\hline \multirow[t]{3}{*}{ Age (Years) } & Mean $\pm \mathrm{SD}$ & $51.4 \pm 13.7$ \\
\hline & $\leq 50$ & $2434(43.7)$ \\
\hline & $>50$ & $3144(56.3)$ \\
\hline \multirow[t]{4}{*}{ BMI $\left(\mathrm{kg} / \mathrm{m}^{2}\right)$} & Mean \pm SD & $27.9 \pm 5.9$ \\
\hline & Normal weight $<25$ & $1632(29.2)$ \\
\hline & Overweight 25-29.9 & $1906(34.1)$ \\
\hline & Obesity $\geq 30.0$ & $2040(36.5)$ \\
\hline \multirow[t]{3}{*}{ Smoking } & Current & $715(12.8)$ \\
\hline & Ex-smoker & $409(7.3)$ \\
\hline & Never & $4454(79.8)$ \\
\hline \multirow[t]{2}{*}{ Type of diabetes } & Type 1 & $536(9.6)$ \\
\hline & Type 2 & $5042(90.4)$ \\
\hline \multicolumn{2}{|l|}{ Insulin use } & $4007(71.8)$ \\
\hline \multirow[t]{3}{*}{ Duration of diabetes (years) } & Mean \pm SD & $8.7 \pm 6.9$ \\
\hline & $\leq 5$ & $2104(37.7)$ \\
\hline & $>5$ & $3474(62.2)$ \\
\hline Hypertension & & $5003(89.6)$ \\
\hline \multicolumn{2}{|l|}{ New hypertension } & $2529(45.3)$ \\
\hline \multicolumn{2}{|l|}{ Controlled hypertension } & $2414(48.2)^{*}$ \\
\hline
\end{tabular}

in the methods. The mean duration of diabetes was $8.7 \pm 6.9$ years and $62.2 \%$ had diabetes for $>5$ years. Hypertensive patients constituted $89.6 \%$ of this study cohort, of which $45.3 \%$ were newly discovered in the center. From hypertensive patients, $48.2 \%$ achieved the target of $\mathrm{BP}<$ $130 / 80 \mathrm{mmHg}$. There was no statistically significant difference between the 2 hypertension groups (controlled vs non-controlled) as regards prevalence of cardiovascular diseases, proteinuria (overt) or mean $\mathrm{HbAlc}$.

Table 2, shows variables associated with hypertension. Hypertension was higher among women than men $(91.0 \mathrm{vs}$ $88.0 \%, \mathrm{p}<0.001)$. The mean age and BMI were higher in the hypertensive group $(52.3 \pm 13.1$ vs $43.5 \pm 15.9$ and 28.2 \pm 5.9 vs $25.2 \pm 5.7$, respectively, $\mathrm{p}<0.001)$. Insulin was used more in the hypertensive group (72.2 vs $68.1 \%, \mathrm{p}=0.03$ ). The duration of diabetes was more in the hypertensive group $(8.9 \pm 6.9$ vs $7.0 \pm 6.3, \mathrm{p}<0.001)$.

The results of the multivariate analyses showed that the factors independently associated with the hypertension (Table 3) were age more than 50 years (OR, $0.4 ; 95 \%$ CI, 0.3 to $0.5 ; \mathrm{p}<0.001)$, BMI $\geq 25$ (OR, $0.5 ; 95 \% \mathrm{CI}, 0.4$ to 0.6 ; 
Table 2. Variables Associated with Hypertension

\begin{tabular}{|l|l|l|l|}
\hline & $\begin{array}{l}\text { Hypertension } \\
\text { n (\%) }\end{array}$ & $\begin{array}{l}\text { No Hypertension } \\
\mathbf{n}(\%)\end{array}$ & p \\
\hline \hline Men & $2180(88.0)$ & $297(51.6)$ & $<0.001$ \\
\hline Women & $2823(91.0)$ & $278(48.3)$ & $<0.001$ \\
\hline Age & $52.3 \pm 13.1$ & $43.5 \pm 15.9$ & $<0.001$ \\
\hline BMI $\left(\mathrm{kg} / \mathrm{m}^{2}\right)$ & $28.2 \pm 5.9$ & $25.2 \pm 5.7$ & 0.06 \\
\hline Smoking & $626(12.5)$ & $89(15.4)$ & 0.03 \\
\hline Insulin use & $3615(72.2)$ & $392(68.1)$ & $<0.001$ \\
\hline $\begin{array}{l}\text { Duration of diabetes } \\
\text { (years) }\end{array}$ & $8.9 \pm 6.9$ & $7.0 \pm 6.3$ & \\
\hline Total & 5003 & 575 & \multirow{2}{*}{} \\
\hline
\end{tabular}

Table 3. Multivariate Analyses for Factors Associated with Hypertension

\begin{tabular}{|l|l|l|l|}
\hline & Odd Ratio & $\begin{array}{l}\text { 95\% Confidence } \\
\text { Interval }\end{array}$ & $\mathbf{p}$ \\
\hline \hline Women & 1.1 & $0.9-1.3$ & 0.3 \\
\hline Age (years) $>50$ & 0.4 & $0.3-0.5$ & $<0.001$ \\
\hline BMI $\geq 25\left(\mathrm{~kg} / \mathrm{m}^{2}\right)$ & 0.5 & $0.4-0.6$ & $<0.001$ \\
\hline Smoking & 0.9 & $0.7-1.2$ & 0.8 \\
\hline Insulin use & 0.6 & $0.5-0.8$ & $<0.001$ \\
\hline $\begin{array}{l}\text { Duration of diabetes } \\
\text { (years) }>5\end{array}$ & 0.6 & $0.5-0.7$ & $<0.001$ \\
\hline
\end{tabular}

$\mathrm{p}<0.001$ ), insulin use (OR, 0.6; 95\% CI, 0.5 to $0.8 ; \mathrm{p}<$ $0.001)$ and duration of diabetes more than 5 years (OR, 0.6; $95 \% \mathrm{CI}, 0.5$ to $0.7 ; \mathrm{p}<0.001)$.

\section{DISCUSSION}

Hypertension was seen in $89.6 \%$ of our patients, using definition of systolic BP of $130 \mathrm{mmHg}$ or above and or diastolic BP $80 \mathrm{mmHg}$ or above, which is one of the highest reported prevalence. Among patients with diabetes mellitus in Jordan [11,12], hypertension was seen in $70-72.4 \%$ (70.9\% of males and $73.9 \%$ of females). The definition of hypertension in that study was BP values of $>130 \mathrm{mmHg}$ systolic or $>80 \mathrm{mmHg}$ diastolic.

Among 1952 Saudi type 2 diabetes mellitus patients, hypertension was present in $78.1 \%(80.5 \%$ of men and $75.8 \%$ of women) using the definition of hypertension based on a pre-existing history of hypertension or systolic BP > $130 \mathrm{mmHg}$ and/or a diastolic BP $>80 \mathrm{mmHg}$ [13]. In US adults with diabetes there was an increased prevalence to $77 \%$ if hypertension was defined as $\geq 130 / 80 \mathrm{mmHg}$ [14].

Of hypertensive diabetic patients in this study, $48.2 \%$ had controlled BP with the ADA target $<130 / 80 \mathrm{mmHg}$.
Although the large majority reported being treated for hypertension, BP was controlled to the currently recommended level of $<130 / 80 \mathrm{mmHg}$ in only $30-40 \%$ of hypertensive, diabetic patients $[15,16]$. In 2001-2002 more than two-thirds of adults with diabetes in the U.S.-Mexico border region had uncontrolled BP [17]. In primary health care in Spain $<10 \%$ of diabetics actually attain BP goals [18]. This control of BP, was even better than glycemic control from the same center, where only $25.6 \%$ of diabetics achieved a target of $\mathrm{HbA} 1 \mathrm{c}<7 \%$ [19].

Current smokers in our study constituted $12.8 \%$ and $70.6 \%$ were overweight or obese, while $15 \%$ of diabetics from Jordan were current smokers, and 91\% were either obese or overweight [12].

In our study, factors independently associated with hypertension were age $>50$ years, $\mathrm{BMI} \geq 25$, insulin use and duration of diabetes $>5$ years, but not with gender or smoking. In Jordan there was a positive and significant association between hypertension and the variables of age, BMI and duration of diabetes, but no significant association was found with gender, or smoking [12]. In patients with type 2 diabetes mellitus, insulin users are at higher risk for development of hypertension [20]. The strength of association showed an approximately 2 -fold increase in odds ratios in patients using insulin for more than 10 years compared with non-users when analyzed in all patients in most of the logistic models. The study by Kern et al., provided direct evidence for the development of insulininduced hypertension [21]. The higher rate of hypertension reported among our study sample is perhaps related to the fact that most diabetic patients have longstanding diabetes and are on insulin.

Until the results of the $8^{\text {th }}$ report of the Joint National Committee appear, we need to stick to BP targets in diabetic patients of $<130 / 80 \mathrm{mmHg}$, though new meta-analysis suggests a systolic BP treatment goal of 130 to $135 \mathrm{mmHg}$ is acceptable [22].

\section{CONCLUSION}

This study confirms that hypertension was seen in $\sim 90 \%$ of diabetic patients in Iraq, and approximately half of them were achieving a target $\mathrm{BP}<130 / 80 \mathrm{mmHg}$.

\section{CONFLICTS OF INTEREST}

Declared none.

\section{ACKNOWLEDGEMENTS}

The authors thank Lesley Pocock for reviewing the manuscript and the staff and patients of Al-Faiha Diabetes and Endocrine Center in Basrah for their contribution to this work.

\section{REFERENCES}

[1] Grossman E, Messerli FH. Diabetic and hypertensive heart disease Ann Intern Med 1996: 15; 125: 304-10.

[2] Bell DS. Treatment of diabetic hypertension. Diabetes Obes Metab 2009; 11: 433-44.

[3] Ostergren J, Poulter NR, Sever PS, et al. ASCOT investigators. The anglo-scandinavian cardiac outcomes trial: blood pressure- 
lowering limb: effects in patients with Type II diabetes. J Hypertens 2008; 26: 2103-11.

[4] American Diabetes Association. Position statement on treatment of hypertension in adults with diabetes. Diabetes Care 2002; 25: 213-29.

[5] American Diabetes Association. Position statement on treatment of hypertension in adults with diabetes. Diabetes Care 2008; 31: s12-s54.

[6] Canadian Diabetes Association. Canadian Diabetes Association 2008 clinical practice guidelines for the prevention and management of diabetes in Canada. Can J Diabetes 2008; 32: S1-S201.

[7] Chobanian AV, Bakris GL, Black HR, et al. Joint National Committee on Prevention, Detection, Evaluation, and Treatment of High Blood Pressure; National Heart, Lung, and Blood Institute; National High Blood Pressure Education Program Coordinating Committee. Seventh Report of the Joint National Committee on Prevention, Detection, Evaluation, and Treatment of High Blood Pressure. Hypertension 2003; 42: 1206-52.

[8] Mancia G, De Backer G, Dominiczak A, et al. Management of Arterial Hypertension of the European Society of Hypertension; European Society of Cardiology: 2007 Guidelines for the Management of Arterial Hypertension: The Task Force for the Management of Arterial Hypertension of the European Society of Hypertension (ESH) and of the European Society of Cardiology (ESC). J Hypertens 2007; 25: 1751-62.

[9] AACE Diabetes Mellitus Clinical Practice Guidelines Task Force. American Association of Clinical Endocrinologists medical guidelines for clinical practice for the management of diabetes mellitus. Endocr Pract 2008; 14: 802-3.

[10] American Diabetes Association. Standards of Medical Care in Diabetes. Diabetes Care 2011; 34: 11s-61s.

[11] Abdel-Aal NM, Ahmad AT, Froelicher ES, Batieha AM, Hamza MM, Ajlouni KM. Prevalence of dyslipidemia in patients with type 2 diabetes in Jordan. Saudi Med J 2008; 29: 1423-8.

[12] Fayzeh M, Mubarak A, Erika S. Froelicher, et al. Hypertension among 1000 patients with type 2 diabetes attending a national diabetes center in Jordan. Ann Saudi Med 2008; 28: 346-51.
[13] Alwakeel JS, Sulimani R, Al-Asaad H, et al. Diabetes complications in 1952 type 2 diabetes mellitus patients managed in a single Institution. Ann Saudi Med 2008; 28: 260-6.

[14] Wong ND, Lopez VA, L'Italien G, Chen R, Kline SEJ, Franklin $\mathrm{S}$. Inadequate control of hypertension in US adults with cardiovascular disease comorbidities in 2003-2004. Arch Intern Med 2007; 167: 2431-6.

[15] Suh D-C, Kim C-M, Choi I-S, Plauschinat CA, Barone JA. Trends in blood pressure control and treatment among type 2 diabetes with comorbid hypertension in the United States: 1988-2004. J Hypertens 2009; 27: 1908-16.

[16] Resnick HE, Foster GL, Bardsley J, Ratner RE. Achievement of American Diabetes Association clinical practice recommendations among U.S. adults with diabetes, 1999-2002: the National Health and Nutrition Examination Survey. Diabetes Care 2006; 29: 531-7.

[17] Vijayaraghavan M, He G, Stoddard P, Schillinger D. Blood pressure control, hypertension, awareness, and treatment in adults with diabetes in the United States-Mexico border region. Rev Panam Salud Publica 2010; 28: 164-73.

[18] Escobar C, Barrios V, Calderón A, et al. Diabetes mellitus in hypertensive population attended in primary care in Spain. Blood pressure and lipid control rates. Rev Clin Esp 2007; 207: 221-7.

[19] Mansour AA, Wanoose HL, Odaa AH. A three year cohort prospective type 2 diabetes control study in Basrah. J Diabetes Metab 2011;2: 2.

[20] Tseng CH. Exogenous insulin use and hypertension in adult patients with type 2 diabetes mellitus. Arch Intern Med 2006; 166: 1184-9.

[21] Kern W, Peters A, Born J, Fehm HL, Schultes B. Changes in blood pressure and plasma catecholamine levels during prolonged hyperinsulinemia. Metabolism 2005; 54: 391-6.

[22] Bangalore S, Kumar S, Lobach I, Messerli FH. Blood pressure targets in subjects with type 2 diabetes mellitus/impaired fasting glucose: observations from traditional and bayesian randomeffects meta-analyses of randomized trials. Circulation 2011; 123: 2799-810.

This is an open access article licensed under the terms of the Creative Commons Attribution Non-Commercial License (http://creativecommons.org/licenses/ by-nc/3.0/) which permits unrestricted, non-commercial use, distribution and reproduction in any medium, provided the work is properly cited. 